\title{
CRÓNICA CONSTITUCIONAL DEL AÑO 2009
}

MIGUEL ANGEL PRESNO LINERA 
SUMARIO

INSTITUCIONES EUROPEAS Y RELACIONES INTERNACIONALES. PARTIDOS POLÍTICOS Y PROCESOS ELECTORALES. ÓRGANOS CONSTITUCIONALES Y AUTONÓMICOS. ORGANIZACIÓN TERRITORIAL DEL ESTADO. DERECHOS, DEBERES Y LIBERTADES. 


\title{
CRÓNICA CONSTITUCIONAL DEL AÑO 2009
}

\author{
POR \\ MIGUEL ÁNGEL PRESNO LINERA \\ Profesor Titular de Derecho Constitucional \\ Universidad de Oviedo \\ presno@uniovi.es \\ http://www.unioviedo.es/constitucional/miemb/presno.htm \\ blog jurídico: http//presnolinera.wordpress.com
}

Como en años anteriores, en esta Crónica se realiza una presentación de carácter temático y no exclusivamente cronológica, con el propósito de presentar una panóramica más completa de los sucesos relatados. Siguiendo la ordenación de las crónicas precedentes, los bloques temáticos se refieren a las implicaciones para España derivadas de las instituciones europeas y las relaciones internacionales; los partidos políticos y los procesos electorales; los órganos constitucionales y autonómicos; la organización territorial del Estado, y los derechos, deberes y libertades de los ciudadanos.

\section{INSTITUCIONES EUROPEAS Y RELACIONES INTERNACIONALES}

En el ámbito jurisprudencial, y a propósito de los litigios en los que ha sido parte el Estado español y que tienen relación con las materias tratadas en esta crónica, cabe recordar las siguientes sentencias ${ }^{1}$ :

\footnotetext{
${ }^{1}$ Disponibles en http://curia.eu.int/es
} 
1. La Sentencia del Tribunal de Justicia (Sala Octava), de 23 de abril de 2009 (Asunto C-321/08), declaró que:

«el Reino de España ha incumplido las obligaciones que le incumben en virtud de la Directiva 2005/29/CE del Parlamento Europeo y del Consejo, de 11 de mayo de 2005, relativa a las prácticas comerciales desleales de las empresas en sus relaciones con los consumidores en el mercado interior, que modifica la Directiva 84/450/CEE del Consejo, las Directivas 97/7/CE, 98/27/CE y 2002/65/CE del Parlamento Europeo y del Consejo y el Reglamento (CE) n. ${ }^{\circ}$ 2006/2004 del Parlamento Europeo y del Consejo («Directiva sobre las prácticas comerciales desleales»), al no haber adoptado en el plazo fijado las disposiciones legales, reglamentarias y administrativas necesarias para dar cumplimiento a lo dispuesto en la citada Directiva».

2. La Sentencia del Tribunal de Justicia (Sala Sexta), de 14 de mayo de 2009 (Asunto C-266/08), declaró que:

«el Reino de España ha incumplido las obligaciones que le incumben en virtud de la Directiva 2004/81/CE del Consejo, de 29 de abril de 2004, relativa a la expedición de un permiso de residencia a nacionales de terceros países que sean víctimas de la trata de seres humanos o hayan sido objeto de una acción de ayuda a la inmigración ilegal, que cooperen con las autoridades competentes, al no haber adoptado todas las disposiciones legales, reglamentarias y administrativas necesarias para dar cumplimiento a dicha Directiva y al no haber comunicado a la Comisión las disposiciones de Derecho interno que supuestamente contribuyen a llevar a efecto tal conformidad».

3. La Sentencia del Tribunal de Justicia (Sala Quinta), de 9 de julio de 2009 (Asunto C-272/08), declaró que:

«el Reino de España ha incumplido las obligaciones que le incumben en virtud de la Directiva 2004/83/CE del Consejo, de 29 de abril de 2004, por la que se establecen normas mínimas relativas a los requisitos para el reconocimiento y el estatuto de nacionales de terceros países o apátridas como refugiados o personas que necesitan otro tipo de protección internacional y al contenido de la protección concedida, al no haber adoptado, dentro del plazo fijado, todas las disposiciones legales, reglamentarias y administrativas necesarias para dar cumplimiento a lo establecido en dicha Directiva».

4. La Sentencia del Tribunal de Justicia (Sala Primera), de 6 de octubre de 2009 (Asunto C-562/07), declaró que:

«el Reino de España ha incumplido las obligaciones que le incumben en virtud de los artículos 56 CE y 40 del Acuerdo sobre el Espacio Económico Europeo, de 2 de mayo de 1992, al tratar de forma diferente, hasta el 31 de diciembre de 
2006, las ganancias patrimoniales obtenidas en España según que los sujetos pasivos fuesen residentes o no residentes».

5. La Sentencia del Tribunal de Justicia (Sala Séptima), de 1 de octubre de 2009 (Asunto C-502/08), declaró que:

«el Reino de España ha incumplido las obligaciones que le incumben en virtud del artículo 45 de la Directiva 2005/60/CE del Parlamento Europeo y del Consejo, de 26 de octubre de 2005, relativa a la prevención de la utilización del sistema financiero para el blanqueo de capitales y para la financiación del terrorismo, al no haber adoptado todas las disposiciones legales, reglamentarias y administrativas necesarias para dar cumplimiento a lo dispuesto en dicha Directiva y al no haber comunicado a la Comisión de las Comunidades Europeas las disposiciones de Derecho interno que supuestamente contribuyen a garantizar dicho cumplimiento».

6. La Sentencia del Tribunal de Justicia (Sala Primera), de 6 de octubre de 2009 (Asunto C-153/08), declaró que:

«el Reino de España ha incumplido las obligaciones que le incumben en virtud del artículo 49 CE y del artículo 36 del Acuerdo sobre el Espacio Económico Europeo, de 2 de mayo de 1992, al mantener en vigor una legislación fiscal que exime de impuestos los premios obtenidos al participar en las loterías, juegos y apuestas organizados en el Reino de España por determinados organismos públicos y entidades establecidos en dicho Estado miembro y que ejercen actividades de carácter social o asistencial sin ánimo de lucro, sin aplicar la misma exención a los premios de las loterías, juegos y apuestas organizados por organismos y entidades establecidos en otro Estado miembro de la Unión Europea o del Espacio Económico Europeo que ejerzan actividades del mismo tipo».

En lo que tiene que ver con la actividad normativa estatal vinculada a la Unión Europea, hay que hacer mención a la publicación en el BOE de la Ley 24/2009, de 22 de diciembre, de modificación de la Ley 8/1994, de 19 de mayo, por la que se regula la Comisión Mixta para la Unión Europea, para su adaptación al Tratado de Lisboa de 13 de diciembre de 2007 (BOE núm. 308, de 23 de diciembre de 2009).

En el ámbito de la representación parlamentaria, el 9 de junio tuvieron lugar las elecciones al Parlamento Europeo y en lo que respecta a la circunscripción española los 50 diputados resultaron asignados de la siguiente manera: el Partido Popular, con 6.670.232 votos, obtuvo 23; el Partido Socialista Obrero Español, con 6.141.784 votos, 21; la Coalición por Europa, con 808.246 votos, 2; la coalición Izquierda Unida-Iniciativa per Catalunya Verds-Esquerra Unida I Alternativa-Bloque por Asturies-La Izquierda, con 588.248 votos, 2; Unión Progre- 
so y Democracia, con 451.866 votos, 1, y Europa de los Pueblos-Verdes, con 394.938 votos, 1.

Por su parte, el Tribunal Europeo de Derechos Humanos (TEDH) recibió a lo largo del año 2009641 demandas contra España (248 más que en 2008) y condenó al Estado español en 11 ocasiones (9 más que en 2008)²:

1. En el caso Golf de Extremadura S.A. c. España, de 8 de enero de 2009, se condenó a España, de acuerdo con la doctrina del asunto Saez Maeso, de 2004, por lesión del derecho de acceso a los tribunales y al recurso.

2. En el asunto Iribarren Pinillos c. España, de 9 de enero de 2009, el TEDH condenó a España por vulneración de los artículos 3 y 6 del Convenio, al considerar, entre otras cosas, que los tribunales españoles no habían examinado si el uso que las fuerzas de seguridad habían hecho del lanzamiento de botes de humo era estrictamente necesario y proporcionado al objetivo legítimo de poner fin a unos altercados, pues su empleo implicaba necesariamente un riesgo potencial para la integridad física y la vida de las personas presentes.

3. En el caso Igual Coll c. España, y por sentencia de 10 de marzo, el TEDH fundó su fallo en la condena del demandante en un juicio de apelación, sin vista, tras haber sido el absuelto en primera instancia en un procedimiento penal. Se vulneró así el artículo 6 del Convenio en lo que afecta al papel del tribunal de apelación y la naturaleza de las cuestiones sobre las que debía pronunciarse.

4 y 5. En los casos Moreno Carmona c. España y Bendayan Azcantot y Benalal Bendayan c. España, de 9 de junio, se apreció excesiva duración de los procedimientos judiciales respectivos.

6. En el caso C.C. c. España, de 6 de octubre, el Tribunal consideró violado el artículo 8 por la publicación de la identidad y la condición de seropositivo del demandante en una sentencia, pues hubiera bastado que se le identificara con sus iniciales.

7. En el caso Ferré Gisbert c. España, de 13 de octubre de 2009, el Tribunal apreció la vulneración del artículo 6, entendiendo que la motivación ofrecida por el Tribunal Constitucional para inadmitir un recurso de amparo era incoherente con las decisiones de la jurisdicción civil y por la imposición al demandante de una carga desproporcionada que rompía el equilibrio entre el respeto de los requisitos formales de acceso a la jurisdicción constitucional y el derecho de acceso a esa jurisdicción.

8. En el asunto Albizu c. España, resuelto por sentencia de 10 de noviembre,

${ }^{2}$ Disponibles en la página del Tribunal, en inglés y francés http://cmiskp.echr.coe.int 
el TEDH consideró lesionado el artículo 6 por la falta de debida motivación para rechazar el recurso de apelación interpuesto por el demandante.

9. El caso con más repercusión informativa del año 2009 fue el asunto Muñoz Díaz c. España, resuelto por sentencia de 8 de diciembre, donde se apreció vulneración del artículo 14 del Convenio en relación con el 1 del Protocolo n. ${ }^{\circ}$ 1, donde se consideró desproporcionado que el Estado español, tras haber reconocido a la demandante y a su marido la categoría de familia numerosa, haberles otorgado la cobertura de salud y percibido las cotizaciones a la Seguridad Social de su marido, no reconociera los efectos de su «matrimonio gitano» en materia de pensión de viudedad. Y la discriminación se produjo por no darles el mismo tratamiento que en un caso de matrimonio canónico nulo aunque los contrayentes lo considerasen de buena fe válido. El TEDH rechazó que la ausencia de efectos civiles del «matrimonio gitano» constituyera lesión de los artículos 12 (derecho a casarse) y 14 (prohibición de discriminación).

10. En el asunto Llavador Carretero c. España, de 15 de diciembre, se estimó vulnerado el artículo 6 del Convenio, en relación con el derecho de acceso a los tribunales y a un juicio justo.

11. En el caso Gurguchiani c. España, de 15 de diciembre, se examinó la aplicación del artículo 89 del Código Penal, que contempla la sustitución de penas menores de seis años de prisión por la expulsión del extranjero en situación ilegal. El TEDH estimó la vulneración del artículo 7 del Convenio al concluir que la sustitución de la pena de prisión de 18 meses por la expulsión del demandante del territorio nacional por un período de 10 años constituía una pena más grave que la que le correspondía en el momento de los hechos de acuerdo con el contenido que en ese momento tenía el artículo 89.

\section{PARTIDOS POLÍTICOS Y PROCESOS ELECTORALES}

Respecto a las convocatorias electorales a lo largo del año 2009 han de citarse las elecciones a los Parlamentos de las Comunidades Autónomas de Galicia y el País Vasco, celebradas el 1 de marzo.

En Galicia, el Partido Popular obtuvo 789.427 votos y 38 escaños; el PSdeG-PSOE 524.488 votos y 25 escaños, y el Bloque Nacionalista Galego 270.712 votos y 12 escaños. Fue investido como Presidente de la Xunta Alberto Núñez Feijóo.

En el País Vasco, el Partido Nacionalista Vasco obtuvo 396.557 votos y 30 escaños; el Partido Socialista de Euskadi 315.893 votos y 25 escaños; el Partido Popular 144.944 votos y 13 escaños; Aralar 62.214 y 4 escaños; Eusko Alkar- 
tasuna 37.820 votos y 1 escaño; Ezker Batua 36.134 y 1 escaño, y Unión Progreso y Democracia 22.002 y 1 escaño. Fue investido Lehendakari Patxi López.

En cuanto a la ilegalización de partidos o coaliciones electorales deben recordarse varias sentencias del Tribunal Constitucional:

La Sentencia 31/2009, de 29 de enero, desestimó el recurso presentado por Eusko Abertzale Ekintza/Acción Nacionalista Vasca (EAE/ANV) frente a la Sentencia de la Sala Especial del artículo 61 LOPJ del Tribunal Supremo que declaró su ilegalidad y disolución como partido político. El Tribunal concluyó que esa decisión se basaba en una ley constitucional, perseguía un fin legítimo y se fundada en pruebas de actos y conductas singulares que acreditaban su compromiso con el terrorismo.

En el mismo sentido, las Sentencias 43/2009 y 44/2009, de 12 de febrero, rechazaron el amparo solicitado por el partido político Askatasuna y por las agrupaciones electorales Demokrazia 3 Milioi D3M de Álava, Vizcaya y Guipúzcoa frente a la anulación de las candidaturas que habían presentado a las elecciones al Parlamento Vasco. La razón es que continuaban o sucedían, de hecho, la actividad de un partido político ilegal. La Sentencia 44/2009 recuerda que aunque las agrupaciones electorales son distintas a los partidos políticos, también a través de ellas se trataba de obviar la ilegalización de Herri Batasuna.

En sentido contrario, la Sentencia 126/2009, de 21 de mayo, amparó a la coalición electoral «Iniciativa internacionalista-La solidaridad entre los pueblos», formada por los partidos políticos Izquierda Castellana y Comuner@s, pues los indicios que la vinculaban con partidos ilegalizados no eran suficientes, ya la única conexión probada se refería al plano ideológico, y, por sí misma, no bastaba para la anulación de las candidaturas. Por lo demás, la adscripción de 6 de los 64 avalistas de las candidaturas a partidos o candidaturas disueltas por su instrumentalización por ETA no era indicio suficiente, pues la fase de avales carece de control alguno por parte de la candidatura avalada y el aval únicamente expresa el apoyo a que acceda a la competencia electoral; en nada afecta que el avalista sea cargo electo por un partido ilegalizado pues este hecho no limita sus deberes y derechos individuales. El silencio mantenido por los candidatos sobre la violencia terrorista no representa un indicio suficiente para impedir su participación en las elecciones; además la coalición, durante la tramitación del amparo, expresó su condena y rechazo a los medios violentos para la obtención de objetivos políticos.

En lo que respecta a la financiación de los procesos electorales, el Tribunal de Cuentas aprobó, en su sesión plenaria de 26 de marzo de 2009, el Informe de fiscalización de las elecciones generales de 2008. En su comparecencia, el 7 de abril de 2010, ante la Comisión Mixta para las Relaciones con el Tribunal de 
Cuentas, el Presidente de esta institución, D. Manuel Núñez Pérez, sintetizó las conclusiones y recomendaciones de la siguiente manera:

«Las formaciones políticas declararon recursos electorales por un total de 67 millones de euros, de los que 45 millones correspondían a créditos bancarios, 16 millones a anticipos electorales y 6 millones a aportaciones del correspondiente partido. Las aportaciones privadas únicamente alcanzaron los 0,2 millones de euros. En el análisis de estas aportaciones privadas no se detectaron deficiencias reseñables, salvo en algunos casos determinadas carencias en los requisitos de identificación de los aportantes. Por su parte, los gastos declarados ascendieron a 68 millones de euros, de los que 42 millones correspondían a operaciones electorales ordinarias y 26 millones a gastos por envío de propaganda electoral.

Debo resaltar - y el informe lo resalta - la importancia de la cuantía de los gastos por envío de propaganda electoral en relación con los gastos electorales ordinarios, que en muchas formaciones políticas llegaron a ser superiores...

Por lo que afecta al límite máximo de los gastos electorales, se constató que dos formaciones políticas superaron dicho límite: el Partido Popular y Nafarroa Bai. En Nafarroa Bai el exceso fue ligeramente superior a 94.000 euros, importe que excedía el uno por ciento del límite de gastos establecido, por lo que dicha irregularidad fue considerada a efectos de la cuantificación de la propuesta de reducción, por importe de 13.540 euros, de la subvención electoral que le hubiera correspondido percibir por los resultados electorales obtenidos. Por su parte, el exceso del Partido Popular no alcanzó los 16.000 euros, inferior al mencionado uno por ciento del límite de gastos, por lo que no se formuló propuesta de reducción de subvención, siguiendo los criterios técnicos previamente aprobados por el pleno del tribunal para estas elecciones, como antes he señalado, y que, como ya se ha mencionado, son coincidentes con los aplicados en la fiscalización de elecciones precedentes, en las a que algún partido que no ha pasado del uno por ciento tampoco se le aplicó la propuesta de reducción.

Respecto al cumplimiento de las obligaciones legales de terceros hay que destacar que algunos proveedores, cuya identificación se recoge en el informe dentro del apartado de cada partido, incumplieron la obligación de remitir información detallada del importe facturado, a pesar de que se había procedido a recordar específicamente a cada uno de ellos dicha obligación. Debemos señalar, no obstante, que el importe agregado conjunto de lo facturado pendiente de informar por los proveedores no suponía un porcentaje significativo sobre el total de los gastos declarados. Prácticamente es un porcentaje insignificante.

$\mathrm{El}$ informe termina con las naturales recomendaciones, algunas de las cuales, como es natural, se repiten porque hacen referencia a problemas que se han sentido también en la realización de otras campañas electorales, recomendaciones, propuestas y sugerencias que afectan a la normativa electoral expresadas ya en la moción relativa a la modificación de la normativa sobre financiación y fiscalización de los partidos políticos, aprobada por el Pleno en 2001 y elevada a las Cor- 
tes Generales con resolución de esta Comisión mixta de 11 de junio de 2002, moción que efectivamente no ha tenido mucho éxito. Adicionalmente para este proceso se formulan recomendaciones similares a las expresadas en anteriores fiscalizaciones dirigidas, por una parte, a precisar la regulación de la actividad de los gastos por envíos personales y directos de propaganda electoral, a fin de evitar la actual incertidumbre que provoca el gasto no subvencionado sobre el cumplimiento del límite máximo de gastos, así como a establecer los criterios de justificación e imputación de dichos gastos. Asimismo, en otra recomendación se propone acomodar el límite de gasto en publicidad exterior y en prensa periódica y emisoras de radio a los nuevos soportes publicitarios, así como precisar la naturaleza de los gastos a considerar en dichos límites, a efectos de facilitar la comprobación de su cumplimiento.

Por último, se recomienda establecer un adecuado régimen sancionador a las formaciones políticas, sin perjuicio de las competencias atribuidas a la junta electoral competente en el artículo 153 de la LOREG.

\section{ÓRGANOS CONSTITUCIONALES Y AUTONÓMICOS}

Por lo que respecta a la actividad legislativa de las Cortes Generales, se aprobaron a lo largo del año 2009, 3 Leyes Orgánicas ${ }^{3}$ y 29 Leyes Ordinarias ${ }^{4}$.

3 Ley Orgánica 1/2009, de 3 de noviembre, complementaria de la Ley de reforma de la legislación procesal para la implantación de la nueva Oficina judicial, por la que se modifica la Ley Orgánica 6/1985, de 1 de julio, del Poder Judicial (BOE núm. 266, de 4 de noviembre de 2009); Ley Orgánica 2/2009, de 11 de diciembre, de reforma de la Ley Orgánica 4/2000, de 11 de enero, sobre derechos y libertades de los extranjeros en España y su integración social (BOE núm. 299, de 12 de diciembre de 2009); y Ley Orgánica 3/2009, de 18 de diciembre, de modificación de la Ley Orgánica 8/1980, de 22 de septiembre, de Financiación de las Comunidades Autónomas (BOE núm. 305, de 19 de diciembre de 2009). Pueden consultarse su tramitación parlamentaria y el texto oficial en la página del Congreso de los Diputados: http://www.congreso.es/portal/page/portal/Congreso/Congreso/Iniciativas

${ }^{4}$ Ley 1/2009, de 25 de marzo, de reforma de la Ley de 8 de junio de 1957, sobre el Registro Civil, en materia de incapacitaciones, cargos tutelares y administradores de patrimonios protegidos, y de la Ley 41/2003, de 18 de noviembre, sobre protección patrimonial de las personas con discapacidad y de modificación del Código Civil, de la Ley de Enjuiciamiento Civil de la normativa tributaria con esta finalidad (BOE núm. 73, de 26 de marzo de 2009); Ley 2/2009, de 31 de marzo, por la que se regula la contratación con los consumidores de préstamos o créditos hipotecarios y de servicios de intermediación para la celebración de contratos de préstamo o crédito (BOE núm. 79, de 1 de abril de 2009); Ley 3/2009, de 3 de abril, sobre modificaciones estructurales de las sociedades mercantiles (BOE núm. 82, de 4 de abril de 2009); Ley 4/2009, de 15 de junio, de control de precursores de drogas (BOE núm. 145, de 16 de junio de 2009); Ley 5/2009, de 29 de junio, por la que se modifican la Ley 24/1988, de 28 de julio, del mercado de valores, la Ley 
26/1988, de 29 de julio, sobre disciplina e intervención de las entidades de crédito y el texto refundido de la Ley de ordenación y supervisión de los seguros privados, aprobado por Real Decreto Legislativo 6/2004, de 29 de octubre, para la reforma del régimen de participaciones significativas en empresas de servicios de inversión, en entidades de crédito y en entidades aseguradoras (BOE núm. 157, de 30 de junio de 2009); Ley 6/2009, de 3 de julio, por la que se modifica el Estatuto Legal del Consorcio de Compensación de Seguros, aprobado por Real Decreto Legislativo 7/2004, de 29 de octubre, para suprimir las funciones del Consorcio de Compensación de Seguros en relación con los seguros obligatorios de viajeros y del cazador y reducir el recargo destinado a financiar las funciones de liquidación de entidades aseguradoras, y el texto refundido de la Ley de ordenación y supervisión de los seguros privados, aprobado por Real Decreto Legislativo 6/2004, de 29 de octubre (BOE núm. 161, de 4 de julio de 2009); Ley 7/2009, de 3 de julio, de medidas urgentes en materia de telecomunicaciones (procedente del Real Decreto-ley 1/2009, de 23 de febrero) (BOE núm. 161, de 4 de julio de 2009); Ley 8/2009, de 28 de agosto, de financiación de la Corporación de Radio y Televisión Española (BOE núm. 210, de 31 de agosto de 2009); Ley 9/2009, de 6 de octubre, de ampliación de la duración del permiso de paternidad en los casos de nacimiento, adopción o acogida (BOE núm. 242, de 7 de octubre de 2009); Ley 10/2009, de 20 de octubre, de creación de órganos consultivos del Estado en el ámbito agroalimentario y de determinación de las bases de representación de las organizaciones profesionales agrarias (BOE núm. 254, de 21 de octubre de 2009); Ley 11/2009, de 26 de octubre, por la que se regulan las Sociedades Anónimas Cotizadas de Inversión en el Mercado Inmobiliario (BOE núm. 259, de 27 de octubre de 2009); Ley 12/2009, de 30 de octubre, reguladora del derecho de asilo y de la protección subsidiaria (BOE núm. 263, de 31 de octubre de 2009); Ley 13/2009, de 3 de noviembre, de reforma de la legislación procesal para la implantación de la nueva Oficina judicial (BOE núm. 266, de 4 de noviembre de 2009); Ley 14/2009, de 11 de noviembre, por la que se regula el programa temporal de protección por desempleo e inserción (BOE núm. 273, de 12 de noviembre de 2009); Ley 15/2009, de 11 de noviembre, del contrato de transporte terrestre de mercancías (BOE núm. 273, de 12 de noviembre de 2009); Ley 16/2009, de 13 de noviembre, de servicios de pago (BOE núm. 275, de 14 de noviembre de 2009); Ley 17/2009, de 23 de noviembre, sobre el libre acceso a las actividades de servicios y su ejercicio (BOE núm. 283, de 24 de noviembre de 2009); Ley 18/2009, de 23 de noviembre, por la que se modifica el texto articulado de la Ley sobre Tráfico, Circulación de Vehículos a Motor y Seguridad Vial, aprobado por el Real Decreto Legislativo 339/1990, de 2 de marzo, en materia sancionadora (BOE núm. 283, de 24 de noviembre de 2009); Ley 19/2009, de 23 de noviembre, de medidas de fomento y agilización procesal del alquiler y de la eficiencia energética de los edificios (BOE núm. 283, de 24 de noviembre de 2009); Ley 20/2009, de 4 de diciembre, de creación del Consejo General de Colegios Oficiales de Ingeniería en Informática (BOE núm. 293, de 5 de diciembre de 2009); Ley 21/2009, de 4 de diciembre, de creación del Consejo General de Colegios Oficiales de Ingeniería Técnica en Informática (BOE núm. 293, de 05 de diciembre de 2009); Ley 22/2009, de 18 de diciembre, por la que se regula el sistema de financiación de las Comunidades Autónomas de régimen común y Ciudades con Estatuto de Autonomía y se modifican determinadas normas tributarias (BOE núm. 305, de 19 de diciembre de 2009); Ley 23/2009, de 18 de diciembre, de modificación de la Ley 22/2001, de 27 de diciembre, reguladora de los Fondos de Compensación Interterritorial (BOE núm. 305, de 19 de diciembre de 2009); Ley 24/2009, de 22 de diciembre, de modificación de la Ley 8/1994, de 19 de mayo, por la que se regula la Comisión Mixta para la Unión Europea, para su adaptación al Tratado de Lisboa de 13 de diciembre de 2007 (BOE núm. 308, de 23 de diciembre de 2009); Ley 25/2009, de 22 de diciembre, de modificación de diversas leyes para su 
Respecto a las funciones de control parlamentario, debe recordarse la Sentencia del Tribunal Constitucional 190/2009, de 28 de septiembre, sobre la solicitud de varios Diputados del Congreso para que compareciera en la Comisión de Economía y Hacienda el Vicepresidente de la Comisión Nacional del Mercado de Valores al objeto de aclarar hechos denunciados por un medio de comunicación. Esa comparencia había sido rechazada por la Mesa del Congreso alegando que la comparecencia de órganos colegiados había de hacerse a través de su Presidente.

La Sentencia recordó que las normas consuetudinarias parlamentarias referentes a la comparecencia formal de los órganos colegiados a través de su Presidente no pueden restringir la prerrogativa parlamentaria, impidiendo la presencia de otros miembros de este tipo de órganos. Impedir que se pueda oír en sede parlamentaria a cualquier cargo o autoridad por el mero hecho de estar integrado en un órgano introduce una restricción desproporcionada e injustificada en el ejercicio de la iniciativa parlamentaria.

A propósito de los Órganos Auxilares de las Cortes Generales, el Defensor del Pueblo, en el Informe correspondiente al año $2009^{5}$, concluyó, entre otras cosas, lo siguiente:

«... En 2009 se han formulado por los ciudadanos 3.626 quejas de carácter colectivo. O sea, 4.216 quejas colectivas menos en comparación con las planteadas en 2008, lo que si en términos porcentuales supone un descenso del $53,76 \%$, no ha representado, sin embargo, un significativo descenso en el número total de expedientes tramitados, toda vez que se han incrementado las quejas individuales y las promovidas de oficio, en 2.588 y 16 respectivamente. El número total de ciudadanos que han formulado sus quejas a lo largo de 2009, alcanzó la cifra de 79.386, una cifra moderadamente más baja que la registrada en $2008 \ldots$

Tomando en consideración la totalidad de los expedientes de queja gestionados, derivados de las reclamaciones ciudadanas, el número más elevado de ellos

adaptación a la Ley sobre el libre acceso a las actividades de servicios y su ejercicio (BOE núm. 308, de 23 de diciembre de 2009); Ley 26/2009, de 23 de diciembre, de Presupuestos Generales del Estado para el año 2010 (BOE núm. 309, de 24 de diciembre de 2009); Ley 27/2009, de 30 de diciembre, de medidas urgentes para el mantenimiento y el fomento del empleo y la protección de las personas desempleadas (BOE núm. 315, de 31 de diciembre de 2009); Ley 28/2009, de 30 de diciembre, de modificación de la Ley 29/2006, de 26 de julio, de garantías y uso racional de los medicamentos y productos sanitarios (BOE núm. 315, de 31 de diciembre de 2009), y Ley 29/2009, de 30 de diciembre, por la que se modifica el régimen legal de la competencia desleal y de la publicidad para la mejora de la protección de los consumidores y usuarios (BOE núm. 315, de 31 de diciembre de 2009); pueden consultarse su tramitación parlamentaria y el texto oficial en la página del Congreso de los Diputados: http://www.congreso.es/portal/page/portal/Congreso/Congreso/Iniciativas

5 Disponible en http://www.defensordelpueblo.es 
se dirige a las de carácter económico, seguidos de los concernientes a la sanidad y asuntos de carácter social, a la justicia y violencia doméstica y a la ordenación territorial, que incluye además las cuestiones relacionadas con el medio ambiente. En cuanto a variaciones más significativas, cabe citar el aumento registrado respecto del ejercicio anterior en las quejas individuales en materia de "Trabajo y Seguridad Social" y el ligero incremento total observado en las áreas de Defensa e Interior, Justicia y Violencia Doméstica, Inmigración y Asuntos Exteriores, y Educación y Cultura. Por contra, se observa un menor número total en cuanto a gestión de expedientes en los sectores de Administración Económica, Función y Empleo Públicos y Ordenación Territorial...».

En cuanto a la composición del Gobierno, su Presidente, José Luis Rodríguez Zapatero, nombró, en febrero de 2009, a Francisco Caamaño como Ministro de Justicia tras la dimisión de Mariano Fernández; en abril de 2009, el Presidente sustituyó a varios de los miembros del Consejo de Ministros: Elena Salgado pasó a ser Vicepresidenta Segunda y Ministra de Economía y Hacienda; Manuel Chaves Vicepresidente Tercero y Ministro de Política Territorial; José Blanco fue nombrado Ministro de Fomento, Ángel Gabilondo de Educación, Trinidad Jiménez de Sanidad y Políticas Sociales y Ángeles González Sinde de Cultura.

Por lo que se refiere a la actividad legislativa del Gobierno, no se aprobaron Decretos Legislativos pero sí 14 Decretos-Ley ${ }^{6}$.

${ }^{6}$ Real Decreto-ley 1/2009, de 23 de febrero, de medidas urgentes en materia de telecomunicaciones (BOE núm. 47, de 24 de febrero de 2009); Real Decreto-ley 2/2009, de 6 de marzo, de medidas urgentes para el mantenimiento y el fomento del empleo y la protección de las personas desempleadas (BOE núm. 57, de 7 de marzo de 2009); Real Decreto-ley 3/2009, de 27 de marzo, de medidas urgentes en materia tributaria, financiera y concursal ante la evolución de la situación económica (BOE núm. 78, de 31 de marzo de 2009); Real Decreto-ley 4/2009, de 29 de marzo, por el que se autoriza la concesión de garantías derivadas de la financiación que pueda otorgar el Banco de España a favor de Caja de Ahorros de Castilla-La Mancha (BOE núm. 76, de 29 de marzo de 2009); Real Decreto-ley 5/2009, de 24 de abril, de medidas extraordinarias y urgentes para facilitar a las Entidades Locales el saneamiento de deudas pendientes de pago con empresas y autónomos (BOE núm. 101, de 25 de abril de 2009); Real Decreto-ley 6/2009, de 30 de abril, por el que se adoptan determinadas medidas en el sector energético y se aprueba el bono social (BOE núm. 111, de 7 de mayo de 2009); Real Decreto-ley 7/2009, de 22 de mayo, de concesión de un crédito extraordinario al Presupuesto del Ministerio de Industria, Turismo y Comercio, para la ayuda a la adquisición de vehículos y la renovación del parque de vehículos Plan 2000 E, por importe de 100.000.000 de euros (BOE núm. 125, de 23 de mayo de 2009); Real Decreto-ley 8/2009, de 12 de junio, por el que se conceden créditos extraordinarios y suplementos de crédito, por importe total de 19.821,28 millones de euros, y se modifican determinados preceptos de la Ley 38/1992, de 28 de diciembre, de Impuestos Especiales (BOE núm. 143, de 13 de junio de 2009); Real Decreto-ley 9/2009, de 26 de junio, sobre reestructuración bancaria y reforzamiento de los recursos propios de las entidades de crédito (BOE núm. 155, de 27 de junio de 
En el ámbito de los Gobiernos de las Comunidades Autónomas, tras las elecciones parlamentarias de Galicia y el País Vasco fueron elegidos como Presidentes Alberto Núñez Feijóo y Patxi López.

Por lo que al Tribunal Constitucional se refiere, ha de mencionarse, como se recuerda en su Memoria del año 20097, que «si el año 2008 fue el de la transición al nuevo régimen del recurso de amparo establecido con la Ley Orgánica 6/2007, en 2009, coincidiendo con el XXX Aniversario de su Ley Orgánica, el Tribunal ha comenzado a dar plena aplicación sustantiva a las nuevas condiciones procesales de admisibilidad de las demandas, dando a conocer en la STC 155/2009 las pautas definidoras de la categoría de la especial trascendencia constitucional que ha de concurrir en un recurso de amparo para merecer la admisión a trámite. Y si la atención privilegiada que ha sido preciso dispensar al proceso en el que el Tribunal conoce de la impugnación del nuevo Estatuto de Cataluña puede suscitar la impresión de un cierto perjuicio en el normal desarrollo del trabajo de la institución, los datos arrojados por las estadísticas demuestran rotundamente que se trata de una impresión equivocada. Baste decir aquí que durante el año 2009 se han dictado un total de 16.022 resoluciones (el mayor número en toda la historia del Tribunal, que en 2008 ya había alcanzado las 13.353), de las que 15.793 han sido definitivas (por 12.895 en 2008). Un año más, los recursos de amparo finalizados por resolución firme (15.693; 12.833 en 2008) han superado la cifra de los ingresados (10.792), que han vuelto a ser más que en el año precedente (10.279), manteniéndose la pauta del significativo porcentaje representado por los recursos de amparo en materia de extranjería (4.011, que suponen el 37,17 por 100 del total y representan un incremento del 14.01 por 100 respecto de 2008). Ha podido alcanzarse el número de 220 Sentencias (187 en 2008) y 285 Autos (398 en 2008), reduciéndose muy sensiblemente el volumen de los asuntos pendientes de Sentencia, que en el Pleno son ahora 399 (498 en 2008) y 213 en las Salas y Secciones (frente

2009); Real Decreto-ley 10/2009, de 13 de agosto, por el que se regula el programa temporal de protección por desempleo e inserción (BOE núm. 197, de 15 de agosto de 2009); Real Decretoley $11 / 2009$, de 13 de agosto, por el que se regula, para las concesiones de ámbito estatal, la prestación del servicio de televisión digital terrestre de pago mediante acceso condicional (BOE núm. 197, de 15 de agosto de 2009); Real Decreto-ley 12/2009, de 13 de agosto, por el que se aprueban medidas urgentes para paliar los daños producidos por los incendios forestales y otras catástrofes naturales ocurridos en varias Comunidades Autónomas (BOE núm. 197, de 15 de agosto de 2009); Real Decreto-ley 13/2009, de 26 de octubre, por el que se crea el Fondo Estatal para el Empleo y la Sostenibilidad Local (BOE núm. 259, de 27 de octubre de 2009), y Real Decreto-ley 14/2009, de 4 de diciembre, por el que se adoptan medidas urgentes para paliar los efectos producidos por la sequía en determinadas cuencas hidrográficas (BOE núm. 293, de 5 de diciembre de 2009).

7 Disponible en http://www.tribunalconstitucional.es 
a 335 en el año precedente). El dato más espectacular, con todo, es el relativo al número de recursos de amparo pendientes de admisión al finalizar el año 2009: 4.296, prácticamente la mitad que en 2008 (9.015)».

En relación con el control de constitucionalidad de normas legales del Estado, deben citarse, sin ánimo de exhaustividad, las siguientes sentencias ${ }^{8}$ :

1. La Sentencia 45/2009, de 19 de febrero, rechazó que el artículo 171.4 del Código Penal ${ }^{9}$ sea inconstitucional, pues no infringe los principios de igualdad y proporcionalidad ya que: a) el tratamiento punitivo diferenciado tiene como finalidad la protección de bienes tutelados constitucionalmente y que están insuficientemente protegidos en las relaciones de pareja, tales como la vida, la integridad física, la salud, la libertad, la seguridad y la igualdad de las mujeres; b) desde el punto de vista de la igualdad, la necesidad de la diferenciación se fundamenta en que existe un mayor desvalor en las agresiones del hombre hacia la mujer en el ámbito de las relaciones de pareja que en otro tipo de relaciones familiares o afectivas; c) no existe un desequilibrio patente y excesivo entre la sanción y la finalidad de la norma, atendiendo al significativo desvalor mayor de las amenazas en el seno de lo que el Legislador califica como "violencia de género», que es un desvalor relativo a la igualdad, a la libertad y la seguridad de las mujeres en el ámbito de las relaciones de pareja; y d) la diferencia en las consecuencias jurídicas de las normas comparadas tampoco entraña una desproporción porque paralelamente a la pena de prisión se contempla como pena alternativa la de trabajos en beneficio de la comunidad, lo que permite atemperar la sanción penal a la gravedad de la conducta. Tampoco se vulnera el principio de culpabilidad penal porque no se sanciona al agresor por las conductas cometidas por otros cónyuges varones, sino por el especial desvalor de su propia y personal conducta.

2. La Sentencia $127 / 2009$, de 26 de mayo, en coherencia con la citada argumentación, rechazó la inconstitucionalidad del artículo 172.2 del Código Pe-

8 Pueden verse en http://www.tribunalconstitucional.es/JC.htm

9 «El que de modo leve amenace a quien sea o haya sido su esposa, o mujer que esté o haya estado ligada a él por una análoga relación de afectividad aun sin convivencia, será castigado con la pena de prisión de seis meses a un año o de trabajos en beneficio de la comunidad de treinta y uno a ochenta días y, en todo caso, privación del derecho a la tenencia y porte de armas de un año y un día a tres años, así como, cuando el Juez o Tribunal lo estime adecuado al interés del menor o incapaz, inhabilitación especial para el ejercicio de la patria potestad, tutela, curatela, guarda o acogimiento hasta cinco años».

${ }^{10}$ Impone la misma pena al «que de modo leve coaccione a quien sea o haya sido su esposa, o mujer que esté o haya estado ligada a él por una análoga relación de afectividad, aun sin convivencia». 
nal ${ }^{10}$ : el trato penal agravado del delito de coacciones leves no vulnera los principios constitucionales de igualdad, de presunción de inocencia y de culpabilidad, ni los de legalidad y proporcionalidad penal.

3. La Sentencia 81/2009, de 23 de marzo, declaró nulo el artículo 69.3 C) de la Ley 10/1990, de 15 de octubre, del deporte, que tipificaba como infracción administrativa leve «las acciones u omisiones ... que sean contrarias a las normas y reglamentos aplicables a los espectáculos deportivos». La remisión a normas reglamentarias es contraria a la reserva de ley del artículo 25.1 CE.

4. En el mismo sentido, la Sentencia 97/2009, de 27 de abril, declaró nulo el artículo 64 h) de la Ley 7/1996, de 15 de enero, de ordenación del comercio minorista, que tipificaba como infracción leve «el incumplimiento de las obligaciones establecidas en la presente Ley o en las normas dictadas para su desarrollo, que no sean objeto de sanción específica».

5. La Sentencia 89/2009, de 20 de abril, concluyó que el cambio del encuadramiento en la Seguridad Social de los administradores sociales remunerados, que implica la obligación de cotizar con efectos retroactivos, vulnera la Constitución. También declaró nulo el segundo párrafo del artículo 34.5 de la Ley 50/1998, de 30 de diciembre, de medidas fiscales, administrativas y de orden social.

\section{ORGANIZACIÓN TERRITORIAL DEL ESTADO}

Ya se han mencionado las elecciones a los Parlamento de Galicia y el País Vasco y el nombramiento de los Presidentes respectivos.

Si hay una materia objeto de especial atención durante el año 2009 ha sido la de la financiación de las Comunidades Autónomas, que se ha concretado en la aprobación de 3 leyes: la Ley Orgánica 3/2009, de 18 de diciembre, de financiación de las Comunidades Autónomas; la Ley 22/2009, de 18 de diciembre, por la que se regula el sistema de financiación de las Comunidades Autónomas de régimen común y Ciudades con Estatuto de Autonomía y se modifican determinadas normas tributarias, y la Ley 23/2009, de 18 de diciembre, de modificación de la Ley 22/2001, de 27 de diciembre, reguladora de los Fondos de Compensación Interterritorial.

En pocas palabras, cabe recordar que, con estas previsiones, el criterio de la población es reemplazado por el concepto de unidad de necesidad o de población ajustada, que tiene en cuenta la población en relación con la superficie, la dispersión, la insularidad y la edad; en segundo lugar, se cede el 50\% del IRPF y del IVA, y el 58\% de los Impuestos Especiales de fabricación sobre la cerveza, 
el vino y bebidas fermentadas, los productos intermedios, el alcohol y bebidas derivadas, los hidrocarburos y las labores del tabaco; en tercer lugar, la prestación mínima de los servicios públicos esenciales incluye, además de la educación y la sanidad, los servicios sociales; en cuarto término, se crea un Fondo de Garantía de Servicios Públicos Fundamentales para asegurar que cada Comunidad Autónoma recibe los mismos recursos por habitante ajustado para financiar los servicios públicos fundamentales esenciales del Estado de Bienestar; finalmente, a través de los Fondos de Convergencia y Competitividad se articularán los recursos adicionales que aporta el Estado.

Respecto al control de constitucionalidad de normas autonómicas pueden citarse las siguientes sentencias:

1. La Sentencia 13/2009, de 19 de enero, rechazó que la Ley del Parlamento Vasco 4/2005, de 18 de febrero, para la igualdad de mujeres y hombres, fuera inconstitucional, tanto por razones competenciales como sustantivas: esa norma no invade competencias del Estado porque, en el momento de resolver el recurso, ya se había reformado la Ley orgánica de régimen electoral general a través de la Ley Orgánica 3/2007, para la igualdad efectiva de mujeres y hombres, que dispone que en las elecciones a las Asambleas autonómicas «las leyes reguladoras de sus respectivos regímenes electorales podrán establecer medidas que favorezcan una mayor presencia de mujeres en las candidaturas»; en el ámbito sustantivo, y aplicando la doctrina de la STC 12/2008, se rechaza que la norma sea limitativa del ejercicio del derecho al sufragio pasivo o establezca vínculos más estrechos entre electores y elegibles en función del sexo que compartan.

2. La Sentencia 55/2009, de 9 de marzo, declaró nula la previsión legal de Baleares que mantenía diferencias retributivas entre su personal y el transferido desde la Administración del Estado al no respetar el marco constitucional.

3. En el mismo sentido, la Sentencia 86/2009 anuló una disposición de la Ley de la función pública de Canarias sobre la fijación del sueldo de los funcionarios públicos de esa Comunidad.

4. La Sentencia 106/2009, de 4 de mayo, declaró inconstitucional un precepto de la Ley de Comercio de Cantabria sobre limitación temporal para el desarrollo de específicas modalidades de venta, pues se trata de normas de competencia estatal.

5. La Sentencia 130/2009, de 1 de junio, declaró nulas las previsiones de una Ley foral que establecía pruebas restringidas para acceder a la condición de secretario o interventor de las entidades locales de Navarra.

6. La Sentencia 162/2009, de 29 de junio, enjuiciando la legislación aragonesa sobre enajenación de los bienes patrimoniales de las Administraciones lo- 
cales, concluyó que una vez que el Legislador estatal ha aprobado la normativa básica en dicha materia, la autonómica debe ajustarse a ella, por lo que los efectos de la inconstitucionalidad sobrevenida y nulidad serán sólo a partir de la fecha de entrada en vigor de la Ley estatal.

En materia de conflictos hay que reseñar:

1. La Sentencia 136/2009, de 15 de junio, donde se concluyó que las subvenciones para apoyar la energía solar térmica convocadas por el Instituto para la Diversificación y Ahorro de la Energía infringen el orden constitucional de competencias pues su objeto eran actividades propias la competencia autonómica, sin elementos que requiriesen gestión centralizada.

2. La Sentencia 138/2009, de la misma fecha, declaró que las competencias controvertidas - ayudas a la investigación en materias relacionadas con la Red de Parques Nacionales- eran de la Junta de Andalucía, al ser materia relativa a espacios naturales protegidos y medio ambiente.

3. La Sentencia 200/2009, de 28 de septiembre, resolvió a favor de la competencia de la Comunidad Autónoma de Galicia respecto a la línea de préstamos con cargo al Fondo financiero del Estado para la modernización de las infraestructuras turísticas, pues el Estado no dispone de un poder general para subvenciones desvinculado del orden competencial.

En lo que a la Administración Local se refiere, conviene recordar la aprobación del Real Decreto-ley 5/2009, de 24 de abril, de medidas extraordinarias y urgentes para facilitar a las Entidades Locales el saneamiento de deudas pendientes de pago con empresas y autónomos, y el Real Decreto-ley $13 / 2009$, de 26 de octubre, que crea el fondo Estatal para el Empleo y la Sostenibilidad Local.

\section{DERECHOS, DEBERES Y LIBERTADES}

En primer lugar, y por seguir la ubicación de las materias en el articulado de la Constitución, ha de mencionarse, en materia de extranjería, la entrada en vigor de la Ley Orgánica 2/2009, de 11 de diciembre, de reforma de la Ley Orgánica 4/2000, de 11 de enero, sobre derechos y libertades de los extranjeros en España y su integración social. Con esta modificación se pretende incorporar, dos años más tarde, la doctrina sobre la materia derivada de la jurisprudencia constitucional, reconociendo el derecho al ejercicio de los derechos de reunión, 
manifestación, asociación, sindicación y huelga a todos los extranjeros, tengan o no autorización de residencia.

La regulación de la asistencia jurídica gratuita, como exige nuestra Constitución, se extiende a todos los órdenes jurisdiccionales; se ha añadido la exigencia de que en los procesos contencioso-administrativos en los que se pretenda recurrir contra las resoluciones que pongan fin a la vía administrativa en materia de denegación de entrada, devolución o expulsión, el reconocimiento del derecho a la asistencia jurídica gratuita requiera una nueva solicitud y la constancia expresa de la voluntad del extranjero de interponer el recurso o ejercitar la acción correspondiente. Parece que el motivo es reducir los recursos presentados por los abogados sin acompañar la manifestación expresa de sus clientes y con el mero propósito de dilatar los procesos.

La redacción del derecho a la educación no parece del todo afortunada: no menciona la educación infantil, que aunque no es obligatoria no debe excluir a los extranjeros, ni aclara si se incluyen para los menores de 18 años tanto los niveles educativos reglados como los no reglados, pudiendo concluirse que los no reglados no estarían garantizados, dado que se alude exclusivamente a la «enseñanza postobligatoria» y ésta comprende "el bachillerato, la formación profesional de grado medio, las enseñanzas profesionales de las artes plásticas y diseño de grado medio y las enseñanzas deportivas de grado medio".

Tampoco parece claro el apartado relativo a los extranjeros mayores de 18 años, pues aunque se alude los que se hallen en España, que tienen derecho a la educación de acuerdo con lo establecido en la legislación educativa, a continuación se habla de "extranjeros residentes», que tienen derecho a acceder a las demás etapas educativas postobligatorias, a la obtención de las titulaciones correspondientes, y al sistema público de becas en las mismas condiciones que los españoles». Sin embargo, como se declaró en la STC 236/2007, «de las disposiciones constitucionales relativas al derecho a la educación, interpretadas de conformidad con la Declaración universal de derechos humanos y los tratados y acuerdos internacionales referidos, se deduce que el contenido constitucionalmente garantizado de ese derecho, en su dimensión prestacional, no se limita a la enseñanza básica, sino que se extiende también a los niveles superiores, aunque en ellos no se imponga constitucionalmente la obligatoriedad y la gratuidad».

Llama también la atención, respecto del reagrupramiento familiar, que si se pretende ajustar la normativa española al acervo comunitario se ignore que el artículo 8 de la Directiva 2003/86/CE del Consejo de 22/09/2003, dispone que «los Estados miembros podrán requerir que el reagrupante haya residido legalmente en su territorio durante un período de tiempo, que no podrá superar dos años, antes de reagrupar a los miembros de su familia con él», mientras que con la 
nueva redacción del artículo 18 se limita la reagrupación de los ascendientes mayores de 65 años a la adquisición de "la residencia de larga duración» (5 años).

Poco antes de esta reforma se publicó la Ley 12/2009, de 30 de octubre, del derecho de asilo y de la protección subsidiaria, que protege, primero, a la persona que se asila «debido a fundados temores de ser perseguida por motivos de raza, religión, nacionalidad, opiniones políticas, pertenencia a determinado grupo social, de género u orientación sexual, [y que] se encuentra fuera del país de su nacionalidad y no puede o, a causa de dichos temores, no quiere acogerse a la protección de tal país»; segundo, al apátrida que, careciendo de nacionalidad y hallándose fuera del país donde antes tuviera su residencia habitual, por los mismos motivos no puede o, a causa de dichos temores, no quiere regresar a él, y, tercero, a las personas de otros países y a los apátridas que, sin reunir los requisitos para obtener el asilo o ser reconocidas como refugiadas, existan motivos fundados para creer que si regresasen a su país de origen en el caso de los nacionales o, al de su anterior residencia habitual en el caso de los apátridas, se enfrentarían a un riesgo real de sufrir alguno de los daños graves previstos en el ar tícu lo 10 de esta Ley, y que no pueden o, a causa de dicho riesgo, no quieren, acogerse a la protección del país de que se trate.

$\mathrm{El}$ asilado o protegido subsidiariamente tiene el derecho a no ser devuelto o expulsado y, además, derecho a la autorización de residencia y trabajo permanente, a la expedición de documentos de identidad y viaje a quienes les sea reconocida la condición de refugiado, y, cuando sea necesario, para quienes se beneficien de la protección subsidiaria; al acceso a los servicios públicos de empleo, a la educación, a la asistencia sanitaria, a la vivienda, a la asistencia social y servicios sociales, a los derechos reconocidos a las personas víctimas de violencia de género, a la Seguridad Social y a los programas de integración, en las mismas condiciones que los españoles; el acceso, en las mismas condiciones que los españoles, a la formación continua u ocupacional y al trabajo en prácticas, así como a los procedimientos de reconocimiento de diplomas y certificados académicos y profesionales y otras pruebas de calificaciones oficiales expedidas en el extranjero, a la libertad de circulación, y al mantenimiento de la unidad familiar.

En cuanto a la igualdad, y en aras a una política positiva hacia la figura del padre, que permita incentivar la implicación de los hombres en las responsabilidades familiares, la Ley 9/2009, de 6 de octubre, dispuso la ampliación del período de paternidad a cuatro semanas, exclusivo para el padre y en los casos de nacimiento, adopción o acogida. La entrada en vigor de estas previsiones se demora al 1 de enero de 2011.

Por lo que respecta a los recursos de amparo, la Sentencia 124/2009, de 18 de mayo, reitera la doctrina de la Sentencia 92/2008, de 21 de julio, que apreció 
discriminación por razón de sexo en el despido de una trabajadora embarazada sin que constase que el empresario conocía su estado ni se hubiese comunicado el embarazo.

Respecto a la protección de la vida y la integridad fisica cabe mencionar la Sentencia 163/2009, de 29 de junio, donde se concluyó que la modificación judicial del régimen de visitas sin oír a un menor que no lo había solicitado y del que ya constaba su opinión, no ha vulnerado la integridad moral del menor. El Tribunal Constitucional sólo puede apreciar una lesión de la integridad psíquica de menores cuando resulte palmaria, manifiesta o del todo indudable; en otro caso la decisión corresponderá siempre a los órganos judiciales competentes.

En relación con la libertad ideológica, ya se mencionó la Sentencia 126/2009, de 21 de mayo, que amparó a la coalición «Iniciativa Internacionalista-La solidaridad entre los pueblos» en su presentación como candidatura a las elecciones del Parlamento Europeo. De acuerdo con la doctrina constitucional, la negativa a condenar expresamente el terrorismo no es indicio bastante para acreditar la voluntad defraudatoria prevista en el artículo 44.4 LOREG; por si fuera poco, en ese caso la condena inequívoca por parte de esa coalición es suficiente contraindicio.

Sobre libertad personal y seguridad, las Sentencias 50/2009, de 23 de febrero, y 122/2009, de 18 de mayo, declararon, primero, que son los Tribunales penales los que deben pronunciarse sobre si es exigible que el condenado comparezca para ser oído antes de resolver sobre la prórroga de prisión provisional, una vez dictada sentencia condenatoria, y, segundo, que el incumplimiento de dicho trámite no pasaría de ser, en su caso, una mera irregularidad del procedimiento sin repercusión en los derechos fundamentales, a menos que se acreditase que el reo había padecido indefensión material.

No obstante, la primera de estas sentencias recuerda que la prórroga de prisión provisional debe argumentarse de forma suficiente y razonable, lo que no había ocurrido en el caso concreto, y la segunda de las sentencias anuló las resoluciones judiciales al entender que no es suficiente la motivación ofrecida en resoluciones previas.

En lo que respecta al derecho al honor y su relación con el derecho a la libertad de información, la Sentencia 29/2009, de 26 de enero, concluyó, a raíz de un artículo periodístico titulado «El hijo xenófobo del concejal recibió 10,5 millones en 2001», que llamar "xenófobo» a una persona supone atribuirle sentimientos de odio, repugnancia u hostilidad a los extranjeros, lo que, en sí mismo, no supone una negación de su dignidad en cuanto persona; no se trata, por tanto, de una expresión formalmente vejatoria que resulte gratuita o innecesaria para la información que se pretendía transmitir. 
En la Sentencia 77/2009, de 23 de marzo, consideró que diversas expresiones referidas a la condición homosexual del afectado, a su actitud y actividad sexual en el momento en que había sido detenido, son formalmente injuriosas en el contexto empleado; por la forma en que fueron difundidas carecían de trascendencia informativa y resultaban innecesarias para transmitir la información sobre los hechos objeto de reportaje.

La Sentencia 129/2009, de 1 de junio, sostiene que la afirmación contenida en el reportaje enjuiciado de que una mujer, víctima de un asesinato, regentaba un negocio de prostitución, que su domicilio era un prostíbulo o que se dedicaba a la prostitución desde muy joven, eran datos de contenido vejatorio y el informador no realizó la debida actividad para su contraste.

Respecto a la propia imagen, la Sentencia 77/2009, de 23 de marzo, declaró que la publicación de fotografías íntimas, captadas en el ámbito privado, en las que aparecen los cuerpos desnudos o semidesnudos de unas personas sin su consentimiento, es una intromisión en sus derechos a la intimidad y a la propia imagen y su difusión carece de interés público.

En cuanto a la protección de datos, la Sentencia 70/2009, de 23 de marzo, recordó que los datos sobre la salud física y psíquica de las personas son íntimos y especialmente sensibles. En el caso concreto se utilizaron sin apoyo legal ni consentimiento del interesado.

En el mismo sentido, la Sentencia 159/2009, de 29 de junio, concluyó que si están plenamente justificados los controles médicos para determinar la capacidad física y psíquica de los aspirantes a un cuerpo policial en un determinado procedimiento, ello no implica una habilitación para que se produzca el intercambio de datos médicos entre las diversas Administraciones que convocan procesos selectivos para distintas fuerzas policiales.

A propósito de la inviolabilidad de domicilio y el secreto de las comunicaciones, la STC 197/2009, de 28 de septiembre, destaca, primero, que al registro de una furgoneta no le son aplicables las garantías previstas para este derecho, pues ese vehículo no tenía la condición de domicilio; tampoco es lesivo del derecho que el registro se realice de madrugada pues en la autorización judicial se decía que la diligencia se llevaría a cabo en horas nocturnas.

Respecto a las comunicaciones, se estimó vulnerado parcialmente porque los Autos que autorizaron las escuchas telefónicas no contenían una motivación suficiente: se afirma que existe un delito de tráfico de drogas, una organización dedicada al mismo y la participación en él de la persona investigada, sin expresar, ni siquiera de modo genérico, los datos objetivos en los que se fundamentaban esas afirmaciones. No cabe justificar a posteriori los elementos objetivos indiciarios que pudieran servir de soporte a la investigación. 
En relación con los derechos del artículo 20, en el ámbito legislativo se aprobaron la Ley 7/2009, de 3 de julio, de medidas urgentes en materia de telecomunicaciones (procedente del Real Decreto-ley 1/2009, de 23 de febrero) y la Ley 8/2009, de 28 de agosto, de financiación de la Corporación de Radio y Televisión Española, junto con el Real Decreto-ley 11/2009, de 13 de agosto, que regula, para las concesiones de ámbito estatal, la prestación del servicio de televisión digital terrestre de pago mediante acceso condicional.

Estas normas se sitúan el contexto que describe el Preámbulo de la Ley 8/2009: «El actual estado de cosas aconseja acelerar el proceso de cambio estructural del modelo de financiación de RTVE, renunciar definitiva e inmediatamente a los ingresos publicitarios y pasar a un sistema único de financiación basado en ingresos públicos, amortiguando situaciones de inestabilidad propias de los procesos de transición y consiguiendo que los efectos de la reducción publicitaria en RTVE se dejen sentir lo antes posible en el mercado televisivo".

De acuerdo con la Ley 7/2009, los procesos de integración entre los distintos prestadores del servicio dejarán siempre un mínimo de tres prestadores privados, como instrumento de garantía del pluralismo audiovisual. Por su parte, el Real Decreto-ley 11/2009 prevé la televisión digital terrestre como un negocio reservado a los prestadores privados y limitado a un canal por concesión.

En materia jurisprudencial ya se han mencionado más arriba varias sentencias: la 29/2009 concluyó que llamar "xenófobo» a una persona no supone una expresión formalmente vejatoria que resulte gratuita o innecesaria para la información que se pretendía transmitir; la 77/2009 consideró que diversas expresiones referidas a la condición homosexual del afectado, a su actitud y actividad sexual en el momento en que había sido detenido, son formalmente injuriosas en el contexto empleado; la 129/2009, de 1 de junio, sostiene que la afirmación contenida en el reportaje enjuiciado de que una mujer, víctima de un asesinato, regentaba un negocio de prostitución, que su domicilio era un prostíbulo o que se dedicaba a la prostitución desde muy joven eran datos de contenido vejatorio y el informador no realizó la debida actividad para su contraste.

A propósito del derecho de reunión y manifestación, la Sentencia 10/2009, de 12 de enero, reitera la doctrina de la 71/2008, de 23 de junio, que ya había concluido que en el caso de internos en centros penitenciarios no opera sin más el artículo 21, en cuanto exime de autorización previa de la Administración para reunirse pacíficamente, sino que debe tenerse en cuenta el artículo 25.2 CE.

De la misma manera, las Sentencias 37/2009 y 38/2009, de 9 de febrero, reproducen la doctrina de la STC 170/2008, de 15 de diciembre, que declaró que este derecho no puede ser coartado por el mero hecho de que se pretenda ejercer en período electoral. En estos casos, el amparo fue contra las prohibiciones de la 
Dirección General de Seguridad Ciudadana de la Generalidad de Cataluña para realizar una manifestación a favor del derecho al voto de los inmigrantes y otra por una enseñanza pública de calidad.

Respecto al derecho de asociación, ya se ha citado la Sentencia 31/2009, de 29 de enero, donde se reitera que la declaración de ilegalidad de una formación política por sus relaciones políticas y económicas con la organización terrorista ETA y el partido ilegalizado Batasuna no vulnera el derecho fundamental de asociación.

A propósito del ejercicio del cargo público representativo, también se han mencionado antes la Sentencia 190/2009, de 28 de septiembre, donde se concluyó que las normas consuetudinarias parlamentarias referentes a la comparecencia formal de los órganos colegiados a través de su Presidente no pueden restringir la prerrogativa parlamentaria, impidiendo la presencia de otros miembros de este tipo de órganos.

En el amplísimo catálogo de la tutela judicial deben recordarse, en el plano legal, la Ley Orgánica 1/2009, de 3 de noviembre, complementaria de la Ley de reforma de la legislación procesal para la implantación de la nueva Oficina judicial, por la que se modifica la Ley Orgánica 6/1985, de 1 de julio, del Poder Judicial (BOE núm. 266, de 4 de noviembre de 2009) y la Ley 13/2009, de 3 de noviembre, de reforma de la legislación procesal para la implantación de la nueva Oficina judicial (BOE núm. 266, de 4 de noviembre de 2009).

Ya se han mencionado diversas sentencias del Tribunal Europeo de Derechos Humanos que condenaron a España por vulneración de los derechos del artículo 6 del Convenio, conectados con el que nos ocupa: casos Golf de Extremadura S.A. c. España, de 8 de enero de 2009; Igual Coll c. España, de 10 de marzo; Moreno Carmona c. España y Bendayan Azcantot y Benalal Bendayan c. España, de 9 de junio; Ferré Gisbert c. España, de 13 de octubre; Juez Albizu c. España, de 10 de noviembre, y Llavador Carretero c. España, de 15 de diciembre.

En cuanto a las numerosas sentencias del Tribunal Constitucional que se han pronunciado sobre alguno de los derechos protegidos por el artículo 24 de la Constitución, mencionaremos únicamente algunas de las que consideramos más significativas:

La Sentencia 65/2009, de 9 de marzo, declaró que aunque este derecho fundamental es irrenunciable e indisponible, es constitucionalmente legítima la renuncia a su ejercicio cuando redunde en beneficio del interesado, aunque para ello debe ser explícita, clara, terminante e inequívoca.

La Sentencia 72/2009, de 23 de marzo, estimó lesionado el derecho a la tutela judicial efectiva de un extranjero porque el órgano judicial dejó imprejuz- 
gada la cuestión de fondo al estimar que el recurso había quedado vacío de contenido al haberse realizado ya la expulsión. El Tribunal recuerda que la expulsión es reversible, que implica la prohibición de regresar a España en un plazo de diez años, y que el órgano judicial no respondió a la alegación de que el recurrente ya había cumplido gran parte de su condena.

La Sentencia 75/2009, de 23 de marzo, reiteró que las entidades públicas son titulares del derecho a la tutela judicial efectiva en menor grado que los particulares.

La Sentencia 123/2009, de 18 de mayo, reafirma la vigencia de la doctrina que impide colaborar con el cumplimiento de una pena grave impuesta en el extranjero en un juicio en el que no se oyó al condenado si no se ofrecen posibilidades de defensa ulterior.

La Sentencia 140/2009, de 15 de junio, anuló la expulsión de un extranjero porque el deber de motivación no sólo se refiere a la fundamentación de los hechos y a su calificación jurídica, sino también a la sanción que se impone y en el caso de autos no se indicaron las razones por las que la Administración impuso la expulsión en lugar de la multa. Además, tampoco se tuvo presente el arraigo del recurrente a pesar de que la jurisprudencia del Tribunal Europeo de Derechos Humanos considera que el arraigo familiar es un límite a la expulsión.

La Sentencia 142/2009, de 15 de junio, estimó que el derecho fundamental a no declarar contra uno mismo y a no confesarse culpable no es trasladable de forma automática del proceso penal al procedimiento administrativo sancionador, y que ni se trata de derechos absolutos ni incluye un derecho fundamental a mentir, máxime si se trata de agentes de policía local cuya función modula el ejercicio de sus derechos de defensa.

La Sentencia 155/2009, de 25 de junio, matiza la doctrina del Tribunal sobre el principio acusatorio: antes admitía la imposición de penas superiores a las solicitadas por las acusaciones pero en los límites del tipo penal; esta sentencia declara que no puede imponerse pena que exceda, por su gravedad, naturaleza o cuantía, de la pedida por las acusaciones, aunque no exceda los márgenes previstos para el tipo penal.

La Sentencia 199/2009, de 28 de septiembre, declaró que en un proceso de entrega por euroorden para evitar dicha entrega deben aportarse elementos concretos y determinados sobre el riesgo de sufrir torturas o penas o tratos inhumanos o degradantes. Aunque la Ley 3/2003, sobre orden europea de detención y entrega, no contempla una causa de denegación de entrega por riesgo de torturas o tratos inhumanos, se tratad de una exigencia de la Decisión Marco de la Unión Europea de la que emana la Ley y, en general, del Estado de Derecho. 
La Sentencia 219/2009, de 21 de diciembre, recuerda que la incomunicación de un detenido, que conlleva la imposibilidad de comunicarse con el abogado de libre designación y que le asista uno de oficio no está limitada a los casos de terrorismo y la Ley de enjuiciamiento criminal (artículo 509) la permite mediante una resolución judicial motivada que precise el riesgo de que el detenido pudiera informar o alertar a otros partícipes en el hecho investigado y frustrar la investigación.

En materia de legalidad sancionadora, se aprobó la Ley 18/2009, de 23 de noviembre, por la que se modifica el texto articulado de la Ley sobre Tráfico, Circulación de Vehículos a Motor y Seguridad Vial, aprobado por el Real Decreto Legislativo 339/1990, de 2 de marzo, en materia sancionadora.

En el ámbito jurisprudencial, y en particular sobre el non bis in idem, la Sentencia 1/2009, de 12 de enero, lo considera no vulnerado por la existencia de delitos contra la seguridad del tráfico y por no someterse a las pruebas de alcoholemia (artículos 379 y 380 del Código Penal) pues lo sancionable por el artículo 379 es conducir un vehículo a motor o un ciclomotor bajo la influencia de, entre otras, bebidas alcohólicas, mientras que el artículo 380 castiga la negativa a someterse a pruebas legalmente establecidas para la comprobación de que se conduce bajo la influencia de bebidas alcohólicas. Tampoco lesiona dicho principio, según la Sentencia 91/2009, de 20 de abril, la existencia de delitos de prevaricación medioambiental y contra el medio ambiente pues aunque exista identidad de sujeto y de hecho no la hay en el fundamento.

Por lo que respecta a la libertad sindical, la Sentencia 2/2009, de 12 de enero, declaró que ante la existencia de numerosos indicios de conductas de la empresa lesivas de derechos fundamantales del trabajador representante sindical, que desembocan en su despido, se invierte la la carga de la prueba sobre el carácter discriminatorio del despido y al no haber acreditado la empresa que el despido tuvo causas distintas a la supuesta vulneración de derechos fundamentales, se entendió vulnerada la libertad sindical.

En cuanto a la libertad de empresa y la economía de mercado, se aprobaron diversas leyes; entre ellas, la Ley 3/2009, de 3 de abril, sobre modificaciones estructurales de las sociedades mercantiles; la Ley 11/2009, de 26 de octubre, por la que se regulan las Sociedades Anónimas Cotizadas de Inversión en el Mercado Inmobiliario; la Ley 15/2009, de 11 de noviembre, del contrato de transporte terrestre de mercancías; la Ley 16/2009, de 13 de noviembre, de servicios de pago, y la Ley 17/2009, de 23 de noviembre, sobre el libre acceso a las actividades de servicios y su ejercicio.

No obstante, si una norma tuvo gran relevancia en la materia fue el Real Decreto-Ley 9/2009, de 26 de junio, de reestructuración bancaria y reforzamiento 
de los recursos propios, que, con un fondo de 9.900 millones de euros, se aprobó para favorecer la reestructuración bancaria y reforzar los recursos propios de las entidades.

Sobre derechos sociales relacionados con la familia, se aprobó la Ley 9/2009, de 6 de octubre, de ampliación de la duración del permiso de paternidad en los casos de nacimiento, adopción o acogida. De acuerdo con su Preámbulo, en aras a una política positiva hacia la figura del padre, que permita incentivar la implicación de los hombres en las responsabilidades familiares, la Ley plantea la ampliación del período de paternidad a cuatro semanas, exclusivo para el padre.

En las disposiciones adicionales, se insta al Gobierno a que, en el marco de sus competencias y de acuerdo con las Comunidades Autónomas y los agentes sociales, lleve a cabo campañas de sensibilización con la finalidad de dar a conocer los nuevos derechos que podrán disfrutar los padres e incentivar la distribución a partes iguales de las responsabilidades familiares entre el padre y la madre, así como a presentar anualmente a las Cortes Generales un seguimiento estadístico de las medidas introducidas para conocer su impacto social. La disposición final segunda establece que la Ley entrará en vigor a partir del 1 de enero de 2011.

Sobre seguridad social y protección frente al desempleo se aprobaron la Ley $14 / 2009$, de 11 de noviembre, por la que se regula el programa temporal de protección por desempleo e inserción, y la Ley 27/2009, de 30 de diciembre, de medidas urgentes para el mantenimiento y el fomento del empleo y la protección de las personas desempleadas, que trae causa del Real Decreto-ley 2/2009, de 6 de marzo, de medidas urgentes para el mantenimiento y el fomento del empleo y la protección de las personas desempleadas. El Real Decreto-ley 10/2009, de 13 de agosto, reguló el programa temporal de protección por desempleo e inserción para ampliar la cobertura a los trabajadores que hubieran agotado la protección y carecieran de rentas inferiores al 75\% del salario mínimo interprofesional.

En cuanto a la protección de la salud, se aprobaron la Ley 4/2009, de 15 de junio, de control de precursores de drogas, y la Ley 28/2009, de 30 de diciembre, de modificación de la Ley 29/2006, de 26 de julio, de garantías y uso racional de los medicamentos y productos sanitarios, que, en palabras de su Preámbulo, contempla la participación en la prescripción de determinados medicamentos de otros profesionales sanitarios como son los enfermeros y podólogos, desde el reconocimiento del interés para el sistema sanitario de su participación en programas de seguimiento de determinados tratamientos, cuestión ésta perfectamente asumida en la práctica diaria de nuestro sistema sanitario, y teniendo como objetivo fundamental la seguridad y el beneficio de los pa- 
cientes y de dichos profesionales. Asimismo, contempla la extensión de su participación a la prescripción de productos sanitarios.

En cuanto a las políticas de vivienda, se aprobaron la Ley 19/2009, de 23 de noviembre, de medidas de fomento y agilización procesal del alquiler y de la eficiencia energética de los edificios, y dos importantes normas reglamentarias: el Real Decreto 97/2009, de 6 de febrero, que modifica el Real Decreto 1975/2008, de medidas urgentes a adoptar en materia económica, fiscal, de empleo y acceso a la vivienda, destinado a contribuir al pago de las hipotecas, y el Real Decreto 1961/2009, de 18 de diciembre, que introduce nuevas medidas transitorias en el plan Estatal de vivienda y Rehabilitación 2009-2012, para prolongar la concesión de ayudas propias de la vivienda protegida a la compra der vivienda libre.

Respecto a los derechos de las personas con alguna discapacidad se aprobó la Ley 1/2009, de 25 de marzo, de reforma de la Ley de 8 de junio de 1957, sobre el Registro Civil, en materia de incapacitaciones, cargos tutelares y administradores de patrimonios protegidos, y de la Ley 41/2003, de 18 de noviembre, sobre protección patrimonial de las personas con discapacidad y de modificación del Código Civil, de la Ley de Enjuiciamiento Civil de la normativa tributaria con esta finalidad.

Finalmente, para la protección de los consumidores, se aprobó la Ley 29/2009, de 30 de diciembre, por la que se modifica el régimen legal de la competencia desleal y de la publicidad para la mejora de la protección de los consumidores y usuarios. De acuerdo con su Exposición de Motivos, esta ley nace con el propósito de que la legislación protectora de los consumidores se integre de manera coherente dentro de la regulación del mercado, constituida aquí por la Ley de Competencia Desleal, como forma de asegurar que aquella tutela sea la más efectiva y que la normativa del mercado no quede desintegrada.

Con esta norma se modifica el texto refundido de la Ley General para la Defensa de los Consumidores y Usuarios y otras leyes complementarias, con el objeto de establecer claramente en él que, conforme a la preeminencia del derecho comunitario, las prácticas comerciales de los empresarios dirigidas a los consumidores se rigen únicamente por lo dispuesto en la Ley de Competencia Desleal y en el propio texto refundido de la Ley General para la Defensa de los Consumidores y Usuarios y otras leyes complementarias, sin que quepa imponer a los empresarios o profesionales otras obligaciones, exigencias o prohibiciones distintas de las previstas en dichas normas cuando el título en que éstas se fundan es la protección de los legítimos intereses económicos de los consumidores.

Establecida esta regla general, se aclara, en los términos previstos en la norma comunitaria, la compatibilidad de este régimen con la regulación específica 
dictada por razones ajenas a la protección de los legítimos intereses económicos de los consumidores, con las reglas concretas que regulan las prácticas comerciales en las normas que constituyen transposición de directivas comunitarias dictadas en materia de protección de los consumidores y usuarios y, por último, con las disposiciones más protectoras dictadas en materia de servicios financieros o bienes inmuebles. Igualmente se incorporan al texto refundido de la Ley General para la Defensa de los Consumidores y Usuarios y otras leyes complementarias, las obligaciones de información a los consumidores en aquellas prácticas comerciales que incluyan información sobre las características del bien o servicio y su precio, posibilitando que el consumidor o usuario tome una decisión sobre la contratación.

En un ámbito más concreto, previamente se aprobó la Ley 2/2009, de 31 de marzo, por la que se regula la contratación con los consumidores de préstamos o créditos hipotecarios y de servicios de intermediación para la celebración de contratos de préstamo o crédito. 